\title{
A reeducação das relações étnico-raciais e a série Everybody hates Chris: algumas notas
}

\section{A reeducação das relações étnico-raciais e a série Everybody hates Chris:}

algumas notas

\section{VINÍCIUS OLIVEIRA PEREIRA (iD)}

\begin{abstract}
Resumo
$\mathrm{O}$ artigo analisa os episódios que compõem a primeira temporada do seriado norteamericano Everybody Hates Chris e dialoga com a bibliografia das ciências humanas e sociais sobre a questão racial (NOGUEIRA, 2006), (BICUDO, 1955) a fim de: (1) debater as configurações das relações étnico-raciais no Brasil e nos Estados Unidos; (2) identificar como a questão racial é tratada na série; (3) discutir as possibilidades para a reeducação das relações étnico-raciais no ambiente escolar. As considerações finais do presente artigo perpassam pelo reconhecimento do racismo como um sistema operante no Brasil, apesar da valorização da mestiçagem como elemento formador do povo brasileiro, a compreensão do racismo como processo de não reconhecimento da individualidade de sujeitos negros e a presença de elementos semelhantes entre a questão racial apresentada na série e a realidade social brasileira.
\end{abstract}

Palavras-chave: Educação. Everybody Hates Chris. Racismo. Relações Étnico-Raciais. Seriados.

\section{Abstract}

\section{ABSTRACT}

The article analyzes the first season's episodes of the American sitcom Everybody Hates Chris and discusses with a bibliography of the humanities and social sciences about a racial issue (NOGUEIRA, 2006), (BICUDO, 1975) in order to: (1) discuss the configurations of ethnic-racial relations in Brazil and the United States; (2) identify how the racial issue is presented in the Everybody Hates Chris; (3) discuss the possibilities for the reeducation of ethnic-racial relations in the school. The conclusion of this study are (1) recognition of racism as an operating system in Brazil, despite the appreciation of

\footnotetext{
a Professor da Educação Básica na Rede Municipal de Caxias, RJ, Brasil. Doutorando em Educação pela UERJ, E-mail: viniciusoliveirapereira. Orcid: https://orcid.org/0000-0002-4512-7027
} 
mestizaje as a formative element of the Brazilian people, the understanding of racism as a process of non-recognition of the individuality of black people and the presence of similar elements between the racial issue presented in the Everybody Hates Chris and the Brazilian social reality.

Keywords: Education. Everybody Hates Chris; Racism. Ethnic-Racial Relations. Sitcoms.

\section{RESUMEN}

El artículo analiza los episodios de la primera temporada de la comedia estadounidense Everybody Hates Chris y discute con una bibliografía de las humanidades y las ciencias sociales sobre un tema racial (NOGUEIRA, 2006), (BICUDO, 1975) para: (1) discutir las configuraciones de las relaciones étnico-raciales en Brasil y Estados Unidos; (2) identificar cómo se presenta el problema racial en Everybody Hates Chris; (3) discutir las posibilidades para la reeducación de las relaciones étnico-raciales en la escuela. La conclusión de este estudio es (1) el reconocimiento del racismo como sistema operativo en Brasil, a pesar de la apreciación del mestizaje como un elemento formativo del pueblo brasileño, la comprensión del racismo como un proceso de no reconocimiento de la individualidad de los negros. y la presencia de elementos similares entre el tema racial presentado en Everybody Hates Chris y la realidad social brasileña.

Palabras clave: Educación. Everybody Hates Chris. Racismo. Relaciones étnicoraciales. Comedia de enredo. 


\section{Introdução}

Everybody hates Chris ${ }^{1}$, produzido entre os anos de 2005 a 2009, é uma série televisiva de comédia estadunidense dos canais de televisão United Paramount Network (UPN) e The CW Television Network. A série é narrada pelo comediante afro-americano, Chris Rock ${ }^{2}$, que rememora as lembranças da adolescência vivida em um bairro negro de Nova Iorque, Bedford-Stuyvesant, também conhecido por Bed-Stuy. O personagem principal, Chris Rock, é o filho mais velho de Rochelle Rock e Julius Rock, que têm mais dois filhos: Drew Rock e Tonya Rock.

Rochelle Rock, com o intuito de oferecer uma educação de melhor qualidade para o seu primogênito, decide matriculá-lo em uma escola de um bairro italiano de Nova Iorque, o Colégio Corleone, local onde o Chris tem contato com os demais personagens da série: Joey Caruso (colega de classe do Chris, personagem declaradamente racista e antagonista), Gregory Wuliger (colega de classe e melhor amigo do Chris) e Vivian Morello (professora do Chris) ${ }^{3}$. Chris, que no início da série tem 13 anos de idade, é o único aluno negro da escola em que estuda, situação que intensifica os episódios de racismo vividos pelo personagem.

As características de Todo Mundo Odeia o Chris permitem dizer que trata-se de uma série do gênero sitcom, abreviatura da expressão inglesa situation comedy. Segundo Daniele Crema, entre os elementos que constituem o gênero sitcom, destaca-se: “(...) provocar o prazer a partir do humor compõe a premissa principal no desenvolvimento da sitcom televisiva. Com base nesse propósito, a sitcom se dedica a explorar eventos banais do cotidiano, que podem ocorrer a pessoas comuns, como o próprio telespectador" (CREMA, 2014, p. 29). No que diz respeito aos aspectos técnicos, a autora sinaliza:

(...) prescreve-se que a duração de cada episódio da sitcom varie entre 22 e 25 minutos e há possibilidade de se atingirem 30 minutos com os acréscimos dos comerciais. Na filmagem, geralmente são utilizadas três câmeras no intuito de folicazar ao máximo a expressão dos personagens e pode haver a presença de uma plateia cujas reações às cenas são representadas pelo recurso da trilha de risos (CREMA, 2014, p. 29).

Todos os personagens reúnem um conjunto de características que tornam a série particularmente cômica. No entanto, Daniele Crema pondera a importância do olhar do narrador no processo de produção da graça e destaca sobre quais eixos a série se sustenta:

\footnotetext{
${ }^{1}$ No Brasil, o título da série foi traduzido para Todo Mundo Odeia o Chris. Nas próximas referências ao nome da série será utilizado o título em Língua Portuguesa.

${ }^{2}$ Christopher Julius Rock além de comediante, também atuou como cineasta e roteirista. Seu humor é marcado por uma forte crítica ao racismo estadunidense e as desigualdades raciais que marcam o país.

${ }^{3}$ Há outros personagens secundários na série, mas em termos de relevância para a narrativa e para as reflexões que serão tecidas neste artigo, limitei-me a destacar os três personagens citados.
} 
(...) sob o olhar irônico e satírico do narrador, a sitcom se sustenta basicamente em dois eixos: simultaneamente, retrata as dificuldades financeiras que a família de Chris enfrenta para lidar com os problemas cotidianos e mostra como o protagonista administra as afrontas racistas as quais se submete na escola onde estuda (CREMA, 2014, p. 44).

Entre o público brasileiro, a série alcançou grande popularidade. Em 2006, começou a ser transmitida em tv aberta para todo o país, por meio do canal Record TV. Segundo informações divulgadas em uma matéria do Jornal Folha de São Paulo, a série alcançou, no auge do sucesso, 10 pontos no índice de audiência ${ }^{4}$ na Grande São Paulo, o que representa cerca setecentos e trinta mil, cento e cinquenta domicílios assistindo ao programa. Além de ser sucesso de público, a série foi reconhecida pela crítica especializada. Todo mundo odeia o Chris recebeu várias indicações para prêmios, com destaque para o Globo de Ouro (na categoria melhor série de televisão - musical e comédia) e para o Emmy, uma das premiações de maior prestígio da indústria televisiva americana.

A boa circulação da série entre o público brasileiro foi uma das motivações para a escolha da mesma como tema deste artigo, afinal são muitos os espectadores que podem se tornar interlocutores sobre as temáticas abordadas na série, entre elas o racismo. Conforme sinaliza Oracy Nogueira na década de 50 do século passado:

(...) no Brasil, não é de bom tom "puxar o assunto da cor", diante de uma pessoa preta ou parda. Evita-se a referência à cor, do mesmo modo como se evitaria a referência a qualquer outro assunto capaz de ferir a susceptibilidade do interlocutor - em geral, diz-se que "em casa de enforcado, não se fala em corda" (NOGUEIRA, 2006, p. 299).

Passado-se mais de 50 anos desde que Oracy Nogueira teceu tal afirmação, podemos dizer que ela ainda reflete questões da sociedade brasileira contemporânea. Há um grande receio em se discutir temas que perpassam pela questão racial no Brasil, apesar da raça ser um marcador que atua de forma estrutural sobre nossa sociabilidade. Dessa forma, por mais que a série Todo Mundo odeia o Chris reflita a realidade racial norte americana, considero possível estabelecer pontes de diálogo a fim de pensar as especificidades da questão racial no Brasil.

As discussões que serão tecidas no presente artigo baseiam-se na análise dos episódios que compõem a primeira temporada da série e no diálogo com a literatura das ciências sociais e humanas sobre a questão racial no Brasil e nos Estados Unidos. O exercício realizado neste texto está estruturado, de um modo geral, sobre dois eixos de

\footnotetext{
${ }^{4}$ Notícia divulgada pelo Jornal Folha de São Paulo: $<$ https://f5.folha.uol.com.br/televisao/2019/08/globocompra-direitos-de-todo-mundo-odeia-o-chris-sucesso-de-audiencia-da-record.shtml> Acesso em: 17 de novembro de 2019.

Rev. Caminhos da Educação: diálogos, culturas e diversidades, Teresina, v. 1, n. 3, p. 51-68, set./dez. 2019
} 
discussão: (1) debater, a partir de um viés educacional, as potencialidades da série "Todo Mundo Odeia o Chris" para discussão sobre a reeducação das relações raciais; (2) identificar as especificidades da questão racial no Brasil e nos Estados Unidos.

As relações raciais no Brasil e Estados Unidos: indicações sobre as similaridades e diferenças a partir da série Todo Mundo Odeia o Chris.

Não são raras às vezes em que ouvimos falar que as relações raciais no Brasil são marcadas pela cordialidade e ausência de conflitos. Esse discurso, por vezes, é utilizado, inclusive, como argumento contrário à implementação de políticas públicas específicas com vista a promoção da igualdade étnico-racial. Em um contexto recente, por exemplo, a pessoa indicada pelo atual presidente do Brasil, Jair Bolsonaro, para assumir a presidência da Fundação Cultural Palmares ${ }^{5}$ relativizou a escravidão e o impacto do racismo sobre a realidade social brasileira. Segundo matéria publicada no site do Jornal do Brasil, no dia 10 de dezembro de 2019:

Antes de ser nomeado para o posto, o jornalista afirmou em suas redes sociais que o Brasil tem "racismo nutella" e que o "racismo real" existe nos Estados Unidos. Ele também escreveu que a escravidão foi terrível, "mas benéfica para os descendentes". Na sequência, disse que "negros do Brasil vivem melhor que os negros da África" (JORNAL DO BRASIL, 2019) ${ }^{6}$.

As palavras do indicado ${ }^{7}$ para assumir a presidência da Fundação Cultural Palmares não se configuram como um posicionamento isolado. Elas, na verdade, são tecidas e expressam uma consciência social que resiste em reconhecer a questão racial no processo de produção das desigualdades que marcam o Brasil.

Um dos fatores que pode ajudar a compreender o modo como essa consciência social é tecida é o fenômeno da miscigenação. A compreensão de que somos uma sociedade híbrida tem sido utilizada como argumento contrário à adoção de políticas públicas com foco em determinados grupos étnicos, pois, segundo tal perspectiva, é praticamente inviável distinguir cada um dos grupos étnicos-raciais que compõem a sociedade brasileira.

\footnotetext{
${ }^{5}$ Criada em 1988, a partir da lei 7.668, a Fundação Cultural Palmares, vinculada ao Ministério da Cultura, visa, entre outros objetivos, promover a preservação dos valores culturais, sociais, econômicos decorrentes da influência negra na formação da sociedade brasileira.

${ }^{6}$ A matéria completa pode ser acessada por meio do link: $<$ https://www.jb.com.br/pais/2019/12/1020813nomeado-para-fundacao-palmares-diz-que-orgao-nao-deve-dar-suporte-ao-dia-da-consciencianegra.html>. Acesso em: 12 de dezembro de 2019.

${ }^{7}$ Após uma série de repercussões negativas sobre a indicação do jornalista Sérgio Camargo para o cargo de presidente da Fundação Palmares e de uma ação na justiça que o impedia de tomar posse, o governo federal suspendeu a indicação do mesmo para o cargo.
} 
A noção do Brasil enquanto uma sociedade miscigenada tem sido apontada como um elemento peculiar da identidade nacional e rompe com uma perspectiva que compreendia o fenômeno da miscigenação como um elemento negativo:

Segundo o conde francês Joseph Arthur de Gobineau, em artigo escrito para o periódico francês Le Correspondant, no ano de 1874, intitulado L'émigration au Brésil, os brasileiros seriam uma raça extinta em menos de duzentos anos. Isso por serem, em sua maioria, uma população mestiça, fruto da mestiçagem entre índios, negros e um pequeno número de portugueses (SOUSA, p. 21, 2013).

As considerações tecidas por Gobineau, de certo modo, reverberaram entre a intelectualidade brasileira do século XIX, que foi desafiada a equacionar o desejo de construir a ideia de povo brasileiro, sem levar em consideração o fenômeno da miscigenação (SCHWARCZ, 2008).

A despeito das teorias racistas, que tiveram grande circulação no Brasil, e colocavam-se de forma contundente contra a miscigenação, o início do século XX foi marcado por uma mudança de perspectiva em relação ao fenômeno da miscigenação. Segundo Roberto Damatta, ao longo das primeiras décadas do século passado, consolidou-se um movimento político e intelectual de valorização da miscigenação, que apontava o povo brasileiro como sendo fruto de uma síntese perfeita do melhor que pode existir no negro, no branco e no índio (DAMATTA, 1997, p. 40).

Nessa perspectiva, a construção do povo brasileiro está pautada na miscigenação de três grupos: branco, indígena e negro. Essa maneira de compreender a formação do povo brasileiro foi reforçada por políticos e intelectuais da época, com destaque para Gilberto Freyre, que contribuiu por meio de suas obras para o fortalecimento do mito das três raças e da democracia racial $^{8}$. Giralda Seyferth (1989) reconhece que essa maneira de interpretar a formação do país configurou-se como: “[...] um mito constitutivo, talvez mito de origem, da própria nacionalidade brasileira. A mestiçagem de todos os matizes ainda é a principal figura de retórica a povoar as interpretações sobre a realidade nacional brasileira" (SEYFERTH, 1989, p. 20).

Considero importante dizer que a mestiçagem não é um fenômeno social exclusivo da sociedade brasileira, pois é possível observar em diversos países do mundo a mistura entre diferentes grupos étnicos. Contudo, a utilização da mestiçagem como um

\footnotetext{
${ }^{8}$ Amparados pelas ideias da miscigenação, encontro de culturas e tolerância dos contatos de raça, alguns estudos contribuíram para reforçar a noção de que o Brasil vive uma democracia racial, ou seja, não encontram-se na sociedade brasileira, de acordo com tal perspectiva, conflitos étnico-raciais e desigualdades raciais. Entre os teóricos comumente associados à tal visão, destaca-se Gilberto Freyre (MOTTA, 2007).

Rev. Caminhos da Educação: diálogos, culturas e diversidades, Teresina, v. 1, n. 3, p. 51-68, set./dez. 2019
} 
recurso retórico que singulariza a sociedade nacional produziu especificidades no campo social, como, por exemplo, a ideia de que vivemos em uma democracia racial.

O imaginário coletivo de que vivemos em uma sociedade caracterizada pela ausência de conflitos étnico-raciais é reforçado quando a realidade social brasileira é comparada à de países como África do $\operatorname{Sul}^{9}$ e Estados Unidos ${ }^{10}$, onde até o século passado, leis segregacionistas estavam sendo implementadas ${ }^{11}$. Contudo, o fato de não termos experienciado leis como as que foram implementadas nos países citados não garante a ausência de conflitos raciais ou impede ações discriminatórias.

Nesse momento, penso ser interessante dialogar com o trabalho produzido pelo sociólogo Oracy Nogueira, que dedicou-se a produzir um estudo comparativo sobre as relações raciais no Brasil e nos Estados Unidos. Em uma comunicação intitulada "Preconceito racial de marca e preconceito racial de origem: sugestão de um quadro de referência para a interpretação do material sobre relações raciais no Brasil”, o sociólogo discute as especificidades das dinâmicas raciais nesses dois países:

De um modo geral, tomando-se a literatura referente à situação racial brasileira, produzida por estudiosos ou simples observadores brasileiros ou norte-americanos, nota-se que os primeiros, influenciados pela ideologia de relações raciais característica do Brasil, tendem a negar ou a subestimar o preconceito aqui existente, enquanto os últimos, afeitos ao preconceito, tal como se apresenta este em seu país, não o conseguem "ver", na modalidade que aqui se encontra. Dir-se-ia que o preconceito, tal como existe no Brasil, cai abaixo do limiar de percepção de quem formou sua personalidade na atmosfera cultural dos Estados Unidos (NOGUEIRA, 2006, p. 291).

No entanto, afastando-se das armadilhas presentes no canto da sereia sobre a mestiçagem brasileira e sobre a ausência de práticas discriminatórias de cunho racial no

\footnotetext{
${ }^{9}$ Entre os anos de 1948 a 1994, foram criadas na África do Sul uma série de leis que intensificaram as desigualdades sociais entre brancos e negros naquele país. O conjunto de políticas segregacionistas, que, entre outras coisas, dividiam as cidades a partir de critérios raciais, ficou conhecido como Apartheid.

${ }^{10}$ Durante os séculos XIX e XX, foram implementadas nos Estados Unidos uma série de leis conhecidas como Jim Crow. Tais leis seguiam o princípio "separados, mas iguais". Na prática, a implementação desse conjunto de leis intensificou um quadro de desvantagens econômicas, sociais e políticas para a população negra estadunidense.

${ }^{11}$ Apesar do Brasil não ter vivenciado políticas segregacionistas como o Apartheid e Jim Crow, algumas pesquisas têm demonstrado como o critério racial orientou alguns debates legais. Giralda Seyferth, por exemṕlo, debate como as políticas imigratórias implementadas no período pós-abolição estabeleceram critérios para impedir a imigração de pessoas vindas da África para o Brasil (SEYFERTH, 2002). Outro exemplo que ilustra essa situação é o decreto de 11 de outubro de 1890, que introduz no Código Penal Brasileiro, a proibição da prática da capoeira. Ademais, como demonstra as Diretrizes Curriculares Nacionais para a Educação das Relações Étnico-Raciais e para o Ensino de História e Cultura Afrobrasileira e Africana: "O Decreto $n^{\circ} 1.331$, de 17 de fevereiro de 1854, estabelecia que nas escolas públicas do país não seriam admitidos escravos, e a previsão de instrução para adultos negros dependia da disponibilidade de professores. O Decreto ${ }^{\circ} 7.031$-A, de 6 de setembro de 1878 , estabelecia que os negros só podiam estudar no período noturno e diversas estratégias foram montadas no sentido de impedir o acesso pleno dessa população aos bancos escolares" (BRASIL, 2004, p. 7).
} 
Brasil, Oracy Nogueira aponta o racismo como um mecanismo que atua sobre a realidade social do país. Ao discutir a contribuição do trabalho de Oracy Nogueira para pensar as relações raciais brasileiras, Roberto DaMatta destaca que a tessitura social do Brasil ajudou a sofistificar ainda mais o preconceito:

(...) o nosso preconceito seria muito mais contextualizado e sofisticado do que o norte-americano, que é direto e formal. A consequência disso, sabemos bem, é a dificuldade de combater o nosso preconceito, que em certo sentido tem, pela fato de ser variável, enorme e vantajosa invisibilidade (DAMATTA, 1997, p. 43).

Ao pensar o modo como o racismo se manifesta nos dois países analisados, Oracy Nogueira cria, ou sistematiza o que vinha sendo debatido na literatura sobre o tema, a seguinte categorização: “(...) o preconceito, tal como se apresenta no Brasil, foi designado por preconceito de marca, reservando-se para a modalidade em que aparece nos Estados Unidos a designação de preconceito de origem" (NOGUEIRA, 2006, p. 291).

Após ponderar que ambos os conceitos não devem ser entendidos de maneira absoluta, mas como referências para pensar a realidade social e produzir novas pesquisas, Oracy Nogueira explicita de forma mais detalhada o que entende por preconceito de marca e preconceito de origem:

quando o preconceito de raça se exerce em relação à aparência, isto é, quando toma por pretexto para as suas manifestações os traços físicos do indivíduo, a fisionomia, os gestos, o sotaque, diz-se que é de marca; quando basta a suposição de que o indivíduo descende de certo grupo étnico para que sofra as consequências do preconceito, diz-se que é de origem (NOGUEIRA, 2006, p. 292).

Em um cenário marcada pela dificuldade em reconhecer a existência de racismo no Brasil, o trabalho de Oracy Nogueira traz uma grande contribuição para o campo e aponta, de forma qualitativa, que o racismo não está restrito à sociedades que experienciaram políticas segregacionistas.

A produção teórica do sociólogo citado acima está inserida em um contexto marcado pela realização do Projeto Unesco, um marco importante para o estudo das relações raciais no Brasil:

Na segunda metade dos anos 1940, a Unesco espelhava a perplexidade e a ânsia de inteligibilidade - por parte de intelectuais, comunidade científica e dirigentes políticos - dos fatores que levaram aos resultados catastróficos da $2^{\circ}$ Guerra Mundial em nome da raça. Esse quadro se tornou ainda mais dramático com a persistência do racismo em diversas partes do mundo, o surgimento da Guerra Fria, o processo de descolonização africana e asiática, e a perpetuação de grandes desigualdades sociais em escala planetária.

Diante desse cenário, a UNESCO, munida da razão iluminista, procurou encontrar soluções universalistas que cancelassem os efeitos perversos do racismo. O Brasil foi escolhido, em perspectiva comparada com a negativa experiência racial norte-americana, para ser um dos pólos de investigação dos dilemas vividos pelo mundo ocidental (MAIO, 2007, p. 12). 


\section{A reeducação das relações étnico-raciais e a série Everybody hates Chris: algumas notas}

Como é possível ver, a fama de um país marcado por relações raciais harmônicas alcançou projeção internacional e despertou o interesse da comunidade internacional, ansiosa por identificar relações raciais exitosas e que pudessem ser utilizadas como exemplo para o restante do mundo.

A implementação do Projeto Unesco ajudou a sistematizar, por meio de um volume de recursos financeiros, os estudos sobre as relações raciais no Brasil, marcados, anteriormente, por perspectivas que davam ênfase ao processo de aculturação, a contribuição das culturas africanas à formação da cultura brasileira, o ingresso do negro na sociedade brasileira e a maneira como foi recebido e inserido na dinâmica social (NOGUEIRA, 2006), (MAIO, 2007).

Apesar das críticas que foram feitas a alguns estudos desenvolvidos no âmbito do Projeto Unesco, com destaque para os escritos de Florestan Fernandes, que apontavam o preconceito racial como uma herança da sociedade escravocrata e, portanto, com o surgimento de uma sociedade livre e capitalista, tenderia a ser superado, o Projeto Unesco, por meio de inovações epistemológicas e metodológicas, contribuiu para elucidar o modo como as diferentes faces do racismo operam na sociedade brasileira.

Entre os estudos produzidos no âmbito do Projeto Unesco, considero pertinente destacar, tendo em vista a temática discutida neste artigo, o texto de Virgínia Bicudo ${ }^{12}$, intitulado "Atitudes dos alunos dos grupos escolares em relação a cor de seus colegas", que visa evidenciar: “(1) os sentimentos e os mecanismos psíquicos de defesa manifestos nas atitudes relacionadas com a cor dos colegas; (2) a influência das relações intrafamiliares no desenvolvimento daquelas atitudes" (BICUDO, 1955, p. 227).

A partir de uma série de entrevistas realizadas com estudantes de escolas de São Paulo e seus familiares, Virgínia Bicudo traz a tona aspectos que permeiam as relações raciais entre brancos, negros e amarelos, tecidas no cotidiano de escolas públicas paulistanas. Chama a atenção, de imediato, as similaridades e diferenças entre as narrativas sobre os estudantes negros descritas por Virgínia Bicudo e as desventuras vividas pelo protagonista da série "Todo Mundo Odeia o Chris". O mencionado

\footnotetext{
12 Virgínia Leone Bicudo foi a única mulher a obter o bacharelado em Ciências Políticas e Sociais em 1938, na recém fundada Escola Livre de Sociologia e Política (ELSP). Única socióloga negra a participar do Projeto Unesco, as contribuições de Virgínia Bicudo para o campo das relações raciais no Brasil têm sido visibilidades por trabalhos como a da pesquisadora Janaina Damaceno Gomes. Para maiores informações sobre Virgínia Bicudo, sugiro a leitura da tese "Os Segredos de Virgínia: Estudo de Atitudes e Teorias Raciais na São Paulo dos anos 1940-1950”, escrita por Damaceno.
} 
personagem, único estudante negro da escola em que estuda, é constantemente preterido pelos colegas de classe, que baseados em uma série de estereótipos raciais, negam-se a estabelecer relações de amizade com o ele. Na série, as tensões raciais são explicitadas e, de forma constante, o personagem é vítima de racismo.

Apesar de destacar que não houve menção explícita ao critério racial, como ocorre na série Todo Mundo Odeia o Chris, Virgínia Bicudo demonstrou em sua pesquisa que ao escolher colegas para sentarem juntos, os estudantes lançaram mão de adjetivos ideias para o estabelecimento de relações com os colegas de classe, tais como: bondoso, comportado, aplicado, amável, prestativo. A autora, ao longo do texto, pondera: "as qualidades de 'bom', ‘bom aluno', ‘bem educado' estariam associadas ao branco, como qualidades a êle peculiares" 13 (BICUDO, 1955, p. 240). Nesse sentido, as crianças brancas eram, geralmente, as preferidas no momento de estabelecimento de laços de sociabilidade e amizade, pois reúnem um conjunto de características que as tornavam amigos ideias.

Além de ser preterido pelos colegas de classe, Chris precisa lidar, cotidianamente, com o racismo perpetrado pelo conjunto de professores da escola em que estuda. No episódio onze da primeira temporada, intitulado "todo mundo odeia o natal", a personagem Vivian Morello, professora do Chris, está organizando uma campanha natalina para arrecadar alimentos para famílias carentes. Segue um trecho do diálogo ${ }^{14}$ entre a professora e o personagem principal e uma sequência de imagens da cena:

Morello: turma, como essa é a época da boa vontade. Eu gostaria muito que vocês trouxessem alimentos enlatados para doar aos menos afortunados.

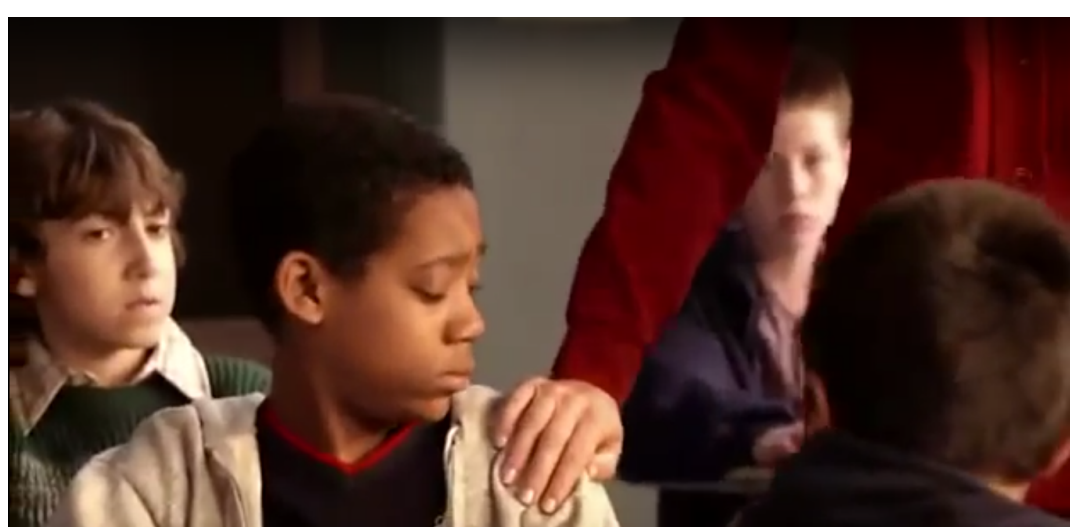

Figura 1

Temporada 1 Episódio 11 - 00:02:45

\footnotetext{
13 Optei por manter a redação original utilizada pela autora, bem como as normas ortográficas do momento em que o texto foi produzido.

${ }^{14}$ Os diálogos transcritos foram retirados da versão dublada da série.

Rev. Caminhos da Educação: diálogos, culturas e diversidades, Teresina, v. 1, n. 3, p. 51-68, set./dez. 2019
} 


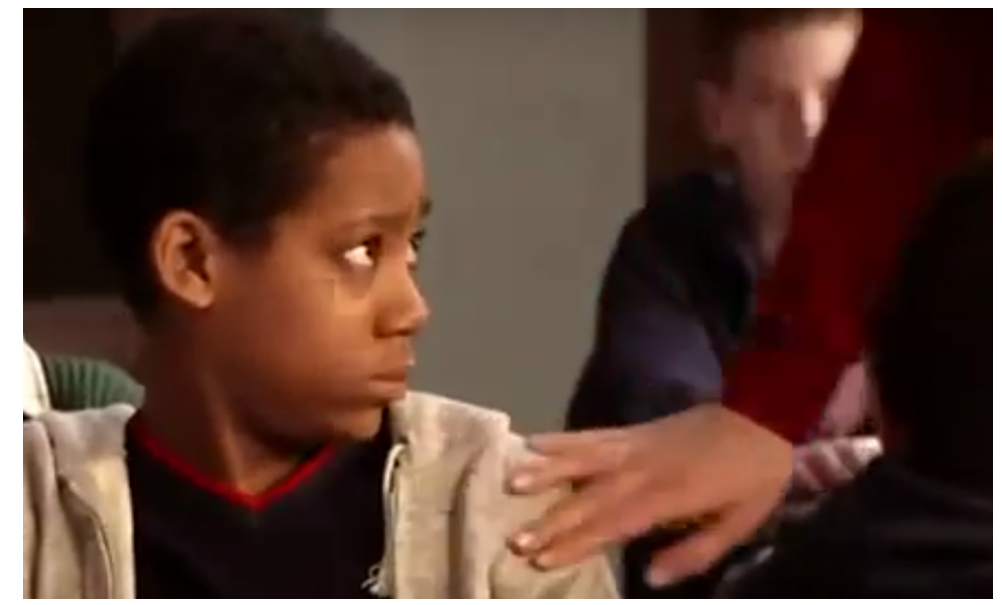

Figura 2

Temporada 1 Episódio 11 - 00:02:46

Chris: Só servem enlatados ou posso trazer comidas em caixa também?

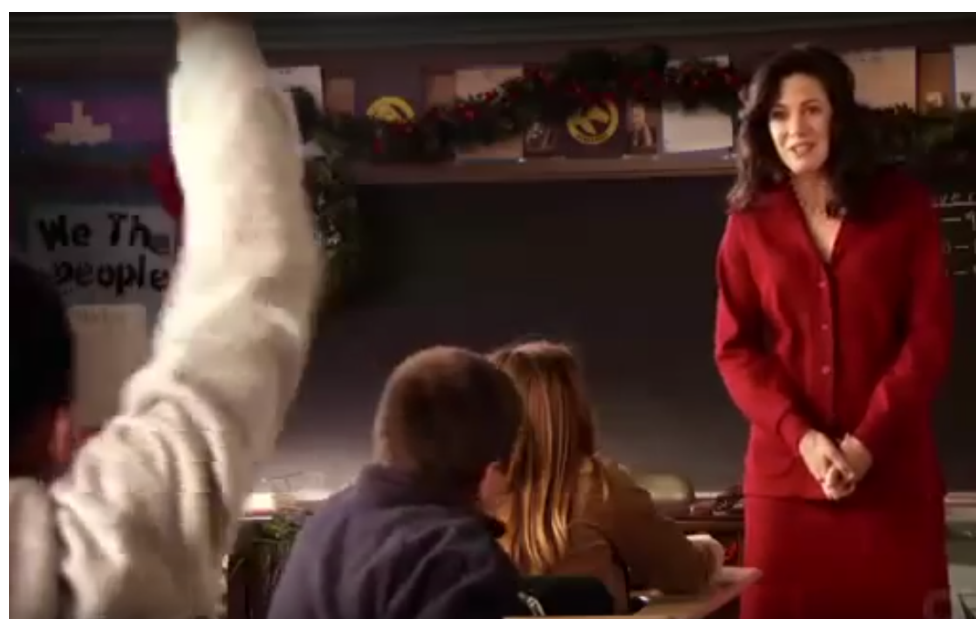

Figura 3

Temporada 1 Episódio 11 - 00:02:50

Morello: Não tem que trazer coisa alguma. Mas foi muito bem pensado. Eu sei que essa época do ano deve ser difícil para a sua família.

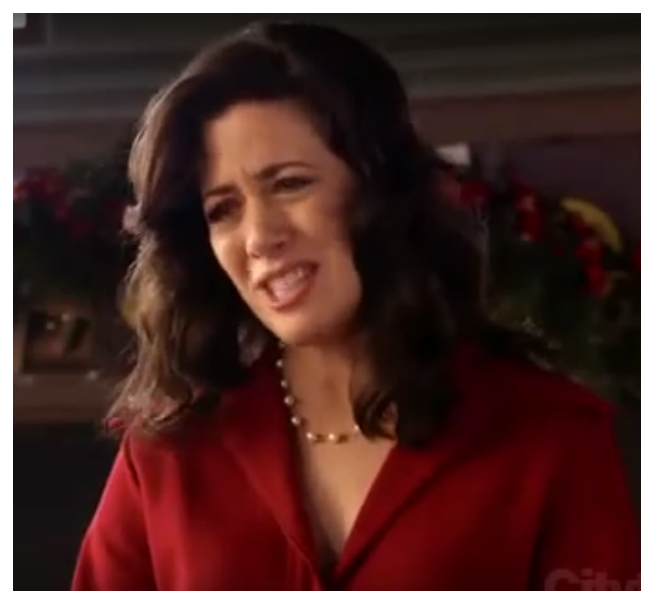

Figura 4

Temporada 1 Episódio 11 - 00:03:03 
Chris: Não, nós vamos indo bem.

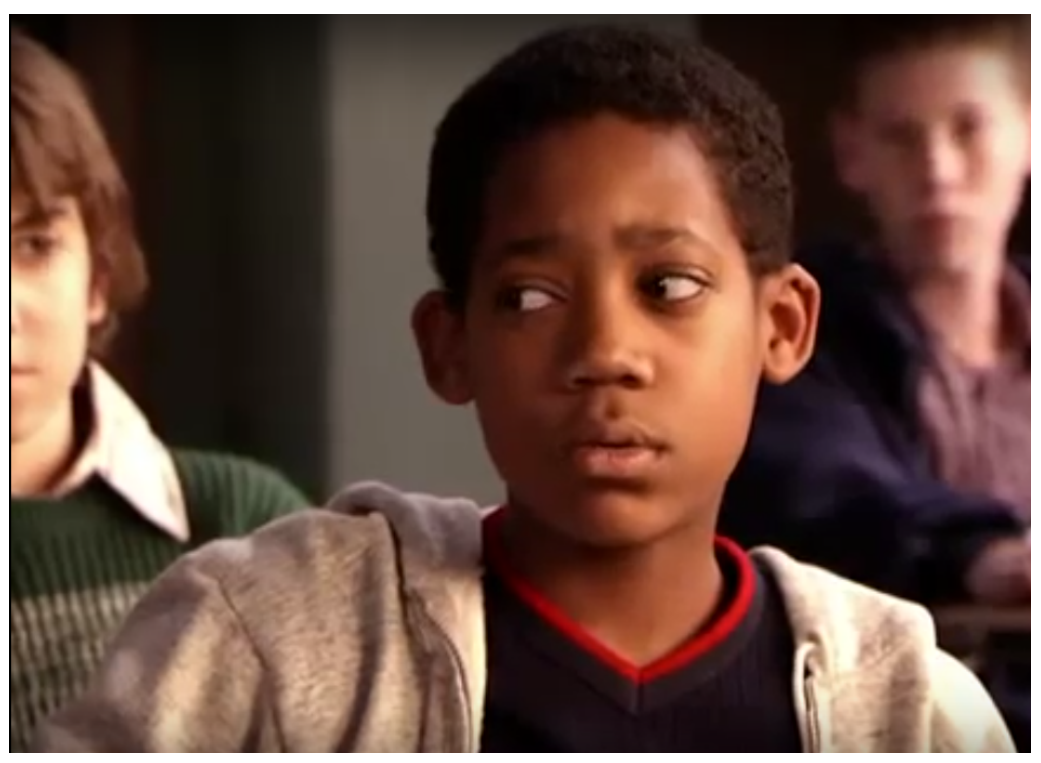

Figura 5

Temporada 1 Episódio 11 - 00:03:05

Morello: Eu sei... Eu sei...

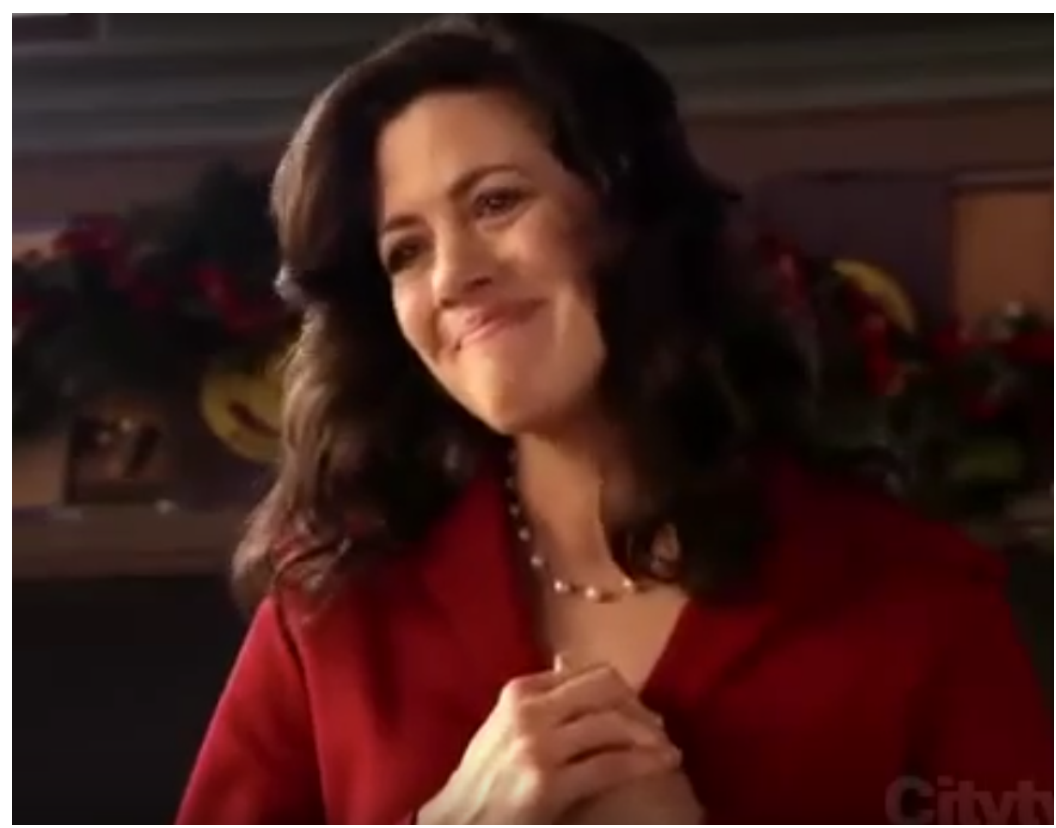

Figura 6

Temporada 1 Episódio 11 - 00:03:10

Apesar da negativa da professora Morello em aceitar a ajuda da família do Chris, o personagem, influenciado por sua mãe, insiste em contribuir para a campanha de arrecadação de alimentos:

Morello: oh, Chris, olha para você. Não precisava trazer comida. Às vezes eu esqueço como a sua gente é resistente. 


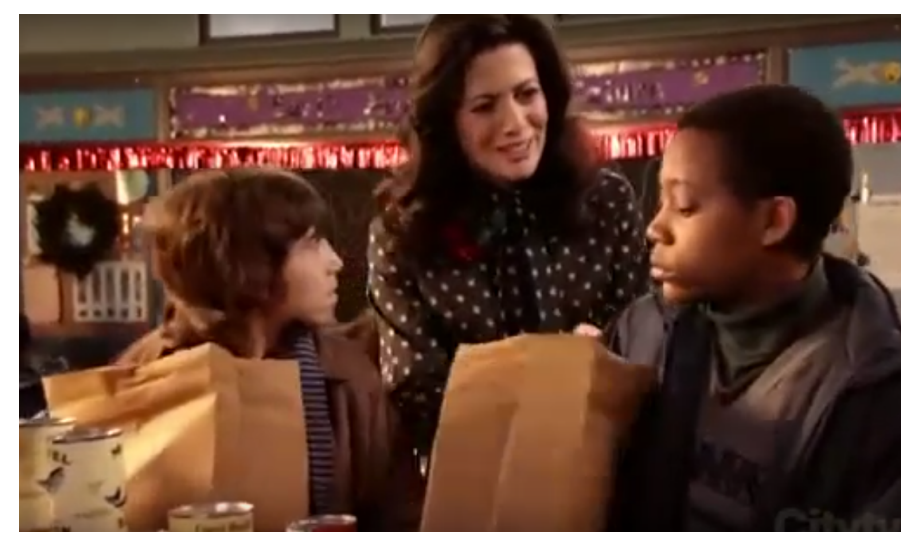

Figura 7

Temporada 1 Episódio 11 - 00:08:57

Chris: minha gente é resistente? Que história é essa?

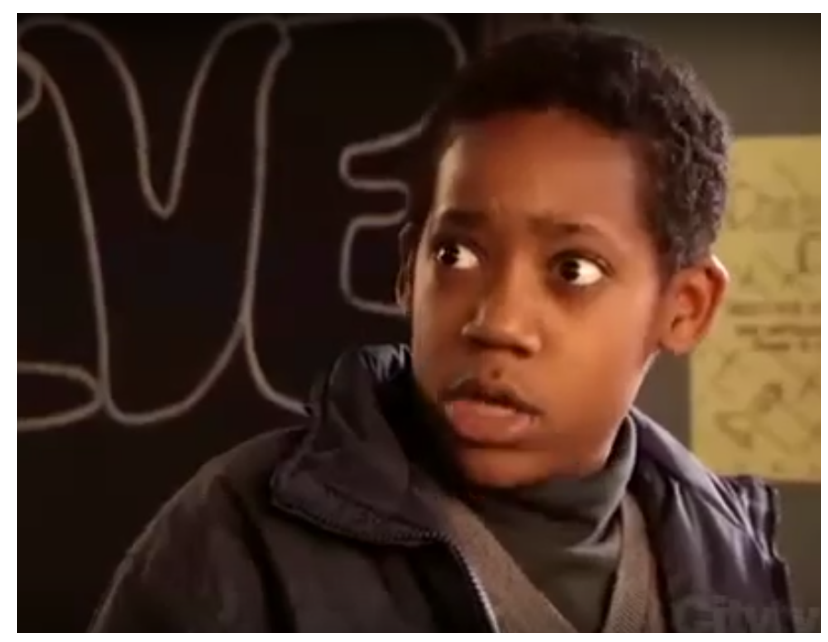

Figura 8

Temporada 1 Episódio 11 - 00:09:05

Morello: que história é essa? Sua gente é resistente? Um dia vocês vão se dar bem. Fale comigo depois da aula, eu trouxe uma coisinha para você.

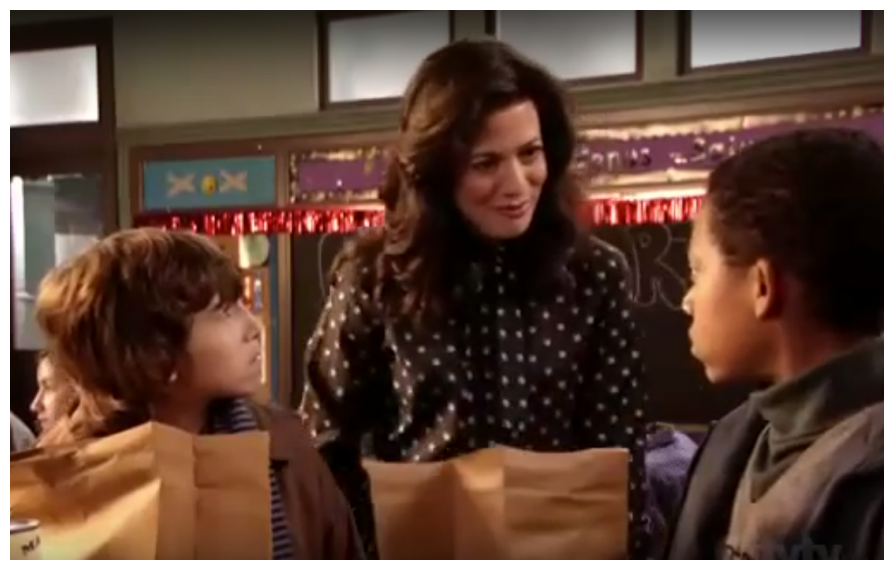

Figura 9

Chris: tudo bem...

Temporada 1 Episódio 11 - 00:09:10 


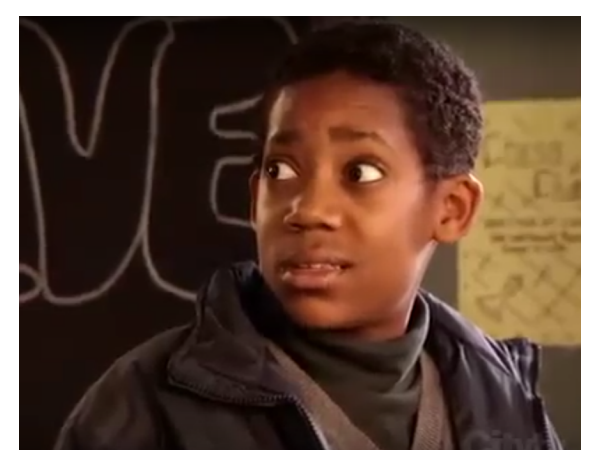

Figura 10

Temporada 1 Episódio 11 - 00:09:17

Ao descrever as características da personagem Vivian Morello, Daniele Crema (2014) diz o seguinte: "a comicidade do papel dessa personagem reside nas tentativas de se mostrar contra o preconceito racial, embora, na realidade, assevere-se uma atitude racista nas entrelinhas de sua fala" (p. 44).

Conforme demonstram a sequência de imagens e os diálogos entre os dois personagens, apesar de compartilhar o mesmo nível socioeconômico dos demais estudantes, a professora pressupõe, baseada única e exclusivamente no fato do Chris ser uma criança negra, que a família dele não tem condições de contribuir com a doação de alimentos. Ademais, amparada por uma caridade que subjuga a população negra, a professora decide doar os alimentos coletados para a família do Chris.

De imediato, é possível imaginar que o diálogo retratado nas páginas anteriores é fruto de um roteiro que carrega nas tintas para destacar a perspectiva racista da personagem Morello e, por esse motivo, está distante da realidade social. No entanto, as leituras sobre a questão racial no campo educacional têm apontado para a presença de discursos e práticas racistas de docentes em sala de aula ${ }^{15}$. Assim como é possível observar práticas racista entre os professores da série "Todo mundo odeia o Chris", Virgínia Bicudo demonstra a presença de discursos racistas entre o conjunto de professoras que participaram de sua pesquisa. A autora destaca um trecho da fala de uma professora:

A professora evidenciou-se ambivalente em suas atitudes para com pessoas de côr, afirmando que nada tem contra o preto, desde que seja educado e em

\footnotetext{
${ }^{15}$ Nos últimos 20 anos, multiplicaram-se os estudos sobre a questão racial no campo educacional. Muitas pesquisas têm sinalizado a presença do racismo como um mecanismo atuante no cotidiano escolar. Um dos estudos pioneiros sobre a temática foi desenvolvido pela pesquisadora Eliane dos Santos Cavalleiro, que dedicou-se a estudar como o racismo se manifesta na educação infantil. Sua pesquisa transformou-se em um livro, "Do silêncio do lar ao silêncio escolar: racismo, preconceito e discriminação na educação infantil",referência importante para aqueles que desejam refletir de forma crítica sobre as dinâmicas raciais no espaço escolar.
} 
seguida negando essa afirmação com a opinião de que não gostaria de ter uma parente preta, porque "o preto é de raça inferior". A opinião da professora segundo a qual o índio se demonstrou superior não se deixando escravizar ao passo que o negro nasceu para ser escravo, é comumente externada por professôres primários em aulas sôbre História do Brasil (BICUDO, 1955, p. 255).

A narrativa trazida por Virgínia Bicudo em sua pesquisa poderia ter sido escrita por um roteirista interessado em reforçar a comicidade de uma personagem racista. No entanto, ela foi dita por uma professora da educação básica, que lidava, cotidianamente, com estudantes negros em sua sala de aula. As relações raciais constituídas em uma sala de aula como a em que Bicudo realizou a pesquisa é extremamente prejudicial não só para estudantes negros, que sofrem com discursos racistas contra seu grupo étnico-racial, mas também para estudantes brancos, que tendem a construir representações equivocadas sobre a população negra.

Apesar de ter produzido a pesquisa ao longo da década de 50 do século $\mathrm{XX}$, os problemas apontados por Virgínia ainda constituem a estrutura escolar. Pesquisas mais recentes têm demonstrado a persistência do racismo nas práticas pedagógicas. Fabiana de Oliveira e Anete Abramowicz, ao realizarem um trabalho de campo em uma creche do interior de São Paulo, destacaram:

A questão racial apareceu nas práticas pedagógicas ocorridas na creche em
situações que demonstravam determinado "carinho", que optamos por chamar
de "paparicação", por parte das professoras em relação a determinadas
crianças, estando as negras, na maior parte do tempo, "fora" ou excluídas
(OLIVEIRA; ABRAMOWICZ. 2010, p. 217). Durante os 6 meses que acompanharam o trabalho desenvolvido na creche pesquisada, as pesquisadoras puderam identificar que crianças negras são menos elogiadas, menos tocadas e recebem menos carinho por parte das professoras.

Situações como as descritas acima evidenciam a necessidade da escola, de um modo geral, e do corpo docente, de modo específico, refletir, criticamente, sobre as práticas produzidas no espaço escolar, a fim de se construir ações que permitam a reeducação das relações étnico-raciais.

\section{Considerações Finais}

Em 2004, o Ministério da Educação publicou as Diretrizes Curriculares Nacionais para Educação das Relações Étnico-Raciais e para o Ensino de História e Cultura Afrobrasileira e Africana. O documento reúne um conjunto de informações sobre como introduzir tais temáticas nas práticas pedagógicas e sinaliza caminhos para reeducar as relações étnico-raciais: 
Para reeducar as relações étnico-raciais, no Brasil, é necessário fazer emergir as dores e medos que têm sido gerados. É preciso entender que o sucesso de uns tem o preço da marginalização e da desigualdade impostas a outros. E então decidir que sociedade queremos construir daqui para frente (BRASIL, 2004, p. 14).

A participação da escola nesse processo é extremamente importante. Nesse sentido, o documento produzido pelo Ministério da Educação destaca: "Para obter êxito, a escola e seus professores não podem improvisar. Têm que desfazer mentalidade racista e discriminadora secular, superando o etnocentrismo europeu, reestruturando relações étnico-raciais e sociais, desalienando processos pedagógicos" (BRASIL, 2004, p. 15).

Um fator que marca a sociabilidade do Chris Rock como jovem negro é ser visto pelos professores a partir de uma perspectiva estereotipada, que define de forma determinista as possibilidades de ser e estar da população negra. Por vezes, ele é visto como um jovem agressivo, fruto de uma família com uma série de problemas sociais. Em outros momentos, ele é visto como um promissor jogador de basquete, profissão compreendida, no imaginário racista, como única alternativa de ascensão social para jovens negros.

Chama atenção a perda da individualidade do sujeito nesse processo, pois às referências da professora ao Chris são sempre pautadas em olhar sobre o grupo étnicoracial de um modo geral. Dessa forma, o personagem deixa de ser uma criança como as outras de sua turma, e passa a ser lido como um representação estereotipada de um determinado grupo étnico-racial. Essa perspectiva se expressa, por exemplo, nos discursos tecidos pela professora Morello: "Às vezes, eu esqueço como a sua gente é resistente"; "Um dia vocês vão se dar bem".

Novamente, retomo a orientação das Diretrizes citadas no início desta seção sobre a importância de se desfazer mentalidades racistas. Quantas vezes o aluno negro é visto como o garoto que criará problemas em sala de aula, a criança problemática, o menino ou o jovem sobre o qual paira uma desconfiança e, por esse motivo, é necessário uma vigilância constante? Nota-se, portanto, que o imaginário racista atua de forma sistemática em sala de aula e projeta, no imaginário do corpo docente, uma visão, muitas vezes deturpada, das crianças e jovens negros:

Se afirmarmos que na escola encontram-se práticas discriminatórias responsáveis pela constituição de representações sociais e identidades prejudiciais a determinados grupos, devemos reconhecer que esta dinâmica conforma a perspectiva dos profissionais que atuam neste espaço (GONÇALVES; PEREIRA, 2013, p. 42).

A escola e os profissionais da educação, comprometidos com a reeducação das relações étnico-raciais, devem estar atentos não somente aos materiais utilizados em sala Rev. Caminhos da Educação: diálogos, culturas e diversidades, Teresina, v. 1, n. 3, p. 51-68, set./dez. 2019 
de aula, mas também às representações e aos discursos perpetrados no cotidiano escolar, colocando em dúvida o que parece trivial e buscando compreender cada estudante negro como um sujeito singular. Por vezes, o racismo encontra-se nos detalhes: no carinho negado e no elogio não dado. Dessa forma, precisamos estar atentos!

\section{Referências}

BICUDO, V. Atitudes dos alunos dos grupos escolares em relação a cor de seus colegas. In: BASTIDE, Roger. Introdução. In: BASTIDE, Roger; FERNANDES, Florestan (Org.). Relações raciais entre negros e brancos em São Paulo. São Paulo: Editora Anhembi/Unesco, 1955. p. 227-310.

BRASIL. Lei $\mathrm{n}^{\circ}$ 7.668, de 22 de agosto de 1988. Autoriza o Poder Executivo a constituir a Fundação Cultural Palmares. Brasília, DF, 1998.

. Diretrizes Curriculares Nacionais para Educação das Relações Étnico-Raciais e para o Ensino de História e Cultura Afro-brasileira e Africana. Ministério da Educação. Brasília, DF, 2004.

CAVALLEIRO, Eliane dos Santos. Do silêncio do lar ao silêncio escolar: racismo, preconceito e discriminação na educação infantil. 3. Ed. - São Paulo: Contexto, 2003.

CREMA, D. Por que todo mundo odeia o Chris? Uma análise discursiva do imaginário de afro-americanidade na série Everybody hates Chris. 2014. 149p. Dissertação (Mestrado). Faculdade de Filosofia, Letras e Ciências Humanas. Universidade de São Paulo, São Paulo, 2014.

GOMES, J. D. Os segredos de Virgínia: estudos de atitudes raciais em São Paulo (19451955). 2013. 166f. Tese (Doutorado) - Faculdade de Filosofia, Letras e Ciências Humanas, Universidade de São Paulo, São Paulo, 2013.

GONÇALVES, M. A. R.; PEREIRA, V. O. . O contexto histórico das politicas racalizadas e a emergência de novas etnicidades. E a emergência do discurso racializado no sistema de ensino: as possibilidades e desafios da lei 10639/03. Teias (Rio de Janeiro. Impresso), v. 14, p. 33-48, 2013.

Nomeado para Fundação Palmares diz que órgão não deve dar suporte ao Dia da Consciência Negra. Jornal do Brasil, Rio de Janeiro, 10 de dezembro de 2019.

OLIVEIRA, Fabiana de; ABRAMOWICZ, Anete. Infância, raça e "paparicação". Educ. rev., Belo Horizonte, v. 26, n. 2, p. 209-226, Aug. 2010.

SCHWARCZ, L. K. M.. O espetáculo das raças, 7a edição. 7. ed. São Paulo: Companhia das Letras, 2008. v. 1. 288p .

SEYFERTH, G.. Colonização, imigração e a questão racial no Brasil. Revista USP, São Paulo, v. 53, p. 117-149, 2002.

. As Ciências Sociais no Brasil e a Questão Racial. In: SILVA, J. da; BIRMAN, P.; WANDERLEY, R. (Org.). Cativeiro e Liberdade. 1. ed. Rio de Janeiro: Ed. UERJ, 1989, p. 11-31.

SOUSA, R. A. S.. A Extinção dos Brasileiros Segundo o Conde Gobineau. Revista Brasileira de História da Ciência, v. 6, p. 21-34, 2013.

RECEBIDO: 21/06/2019

APROVADO:03/08/ 2019
RECEIVED: 21/06/2019

APPROVED: 03/08/ 2019
RECIBIDO: 21/06/ 2019

APROBADO: 03/08/ 2019 
https://doi.org/10.26694/caedu.v1i3.9906 